\title{
Participatory design, temporary structures and the appropriation of urban space by marginalised youth: the problem of the Odd Triangle
}

\author{
Charles Leddy-Owen, Guido Robazza and Lexie Scherer
}

\begin{abstract}
The paper discusses the design and construction of a temporary structure in a neglected urban space. Researchers consulted and worked with members of a youth club in a deprived area of an English city to try to enable spatial appropriation through participatory design. It was found that age-and classbased relationships greatly constrained participants' sense of appropriation. Participants did, however, appropriate the co-design process in enthusiastic ways centred on the transgression of adult norms. The article concludes with reflections on how constraints on marginalised youth agency can inhibit participatory approaches.
\end{abstract}

Key words: Participatory design; temporary structures; youth; children; space; place; class.

\section{Introduction}

This article is based on a project undertaken in the city of Portsmouth, England, which aimed for appropriation of a neglected public space by members (aged 11-19) of a youth club in a deprived urban area. An innovative participatory design approach saw university staff, students and members of the club - pseudonymised as Link Club - involved in 12 weeks of co-design workshops which sought to explore what kinds of temporary timber structure club members would like to be built in an unused urban space the researchers called 'the Odd Triangle' (Figure 1). Once a design was agreed upon, and voted for, by Link Club members, participants were given opportunities to be involved in the construction process itself. Drawing on David Harvey's (2008) notion of the 'right to the city', the core aim of the project was to 'design the marginalised' (Bodnar 2015, 2102) - in this case working-class children and youth - into an urban environment from which they are structurally excluded.

As Cahill $(2007,299)$ suggests, '[t]o advance the field of youth participatory research, we...need selfreflexive accounts of practice evaluating what works and what does not'. The project was only a qualified success in relation to the aim of Link Club members' appropriation of urban space. This will be argued to be largely due to the Odd Triangle's situation in a stigmatised area and its related association among club members with class- and age-related social and spatial power-relations. At the same time, this article also provides examples of some of the surprises, complexities and contradictions that inevitably emerge from a participatory approach (Jenkins \& Carpentier 2013, 267). In particular, the project was far more successful in the appropriation by Link Club members of the participatory design process itself. This was achieved in expressive and enjoyable ways through the carnivalesque pushing of adult boundaries that characterised the club's general social milieu and peergroup dynamics. The imaginative, transgressive and oppositional ideas and practices by which the participatory element succeeded in destabilising adult/youth, researcher/researched hierarchies, however, also carried the project further away from the researchers' goals of spatial appropriation. It will be argued in the conclusion that many such ideas and practices could not have been feasibly designed into the classed, adult-centric city without losing their constitutively fantastical and transgressive character; and that the transformative aims of participatory projects involving adult 
facilitation and disadvantaged youth need to take into account the complex ways by which adult and class norms frame the practices, interests and desires of youth.

\section{Background: the Odd Triangle, Link Club and Portsmouth}

The Odd Triangle is a slightly raised brick foundation of triangular shape measuring approximately 200 square meters. Situated at an intersection close to Portsmouth city centre, near the university and a core commercial area, it serves no specific purpose. Originally built by the council as a development location, it has been left vacant since the 1980s. It is an unused, disconnected and marginal piece of land; a 'void', dead space (Doron 2000) in contrast to the urban design surrounding it. The Odd Triangle is in the path of walking routes to or from the university or shopping areas, and is sometimes populated during the night by queues for a nearby nightclub. It is situated at the end of Guildhall Walk, the principal location of Portsmouth's night-time economy, which has gained a certain notoriety locally from alcohol-fuelled exuberance and violence (BBC 2011).

Figure 1: The 'Odd Triangle' Site

The proposal to build a temporary structure on the Odd Triangle emerged as a follow-up to a previous project organised by one of the co-authors of this paper, Guido Robazza, which saw architecture students from the University of Portsmouth design and construct a temporary timber structure on campus. Following the success of this project, Guido wondered whether the collegiality of this project could harness a similar collective energy if exported to the wider community. In particular, could a scheme of this kind affect how the more marginalised live public space, enabling them to appropriate some of this space and consequently feel more included in the cityscape and built environment? Contacts at Portsmouth City Council were receptive to the idea, suggesting the Odd Triangle space due to its proximity to a deprived residential area and a local youth club, pseudonymised in this article as Link Club, whose members could be involved in the proposed design and construction of a temporary structure. When approaching Link Club staff the idea was again received enthusiastically.

Link Club caters for young people aged 11-19 and aims to provide a 'safe and happy environment' after school hours. The club consists of a large kitchen, where drinks and food are available, four further rooms including spaces for socialising, computer and console access, pool and table tennis facilities, a staff office, and a small outside area with seats and benches. There are a number of regular weekly activities, such as cinema evenings, periodic workshops on topics such as 'moving into work', 'healthy cooking and eating' or bike fixing, and occasional days out for sporting and cultural activities. The club is situated less than half a mile from the Odd Triangle in an area psuedonymised as Solentville. Solentville is close to the centre of Portsmouth and dominated by social housing, much of it high rise, constructed in the 1960s. Densely populated, with little public space, it is one of the most deprived areas of a city struggling to adapt itself to the socioeconomic and geopolitical conditions of the early twenty first century. Though in recent years Solentville has seen a considerable amount of state investment in regeneration projects, much of the area remains in the $10 \%$ most deprived areas in England according to government indices, with one area close to Link Club falling into the most deprived 1\% (Department for Communities and Local Government 2015). In this context, Link Club seemed like a suitable location for the researchers' aim of participatory design enabling the 
appropriation of urban space by the marginalised. The following section will lay out the principles behind this aim in further detail.

\section{The right to the city, temporary structures and participatory design}

As Churchman (2003) argues, cities are not designed for use, particularly independent use, by children, who are among the least considered by urban planners and designers. The project sought to enable Link Club members, as young people living in a deprived area with little or no voice, to 'assert their right to the city' (Schmidt and Németh 2010, 453). David Harvey (2008) suggests that the 'right to the city' is 'the freedom to make and remake our cities', and the project's core goal was to facilitate club members' appropriation of a particular public space in a way that would 'design the marginalised in[to]' the urban environment (Bodnar 2015, 2102). The researchers hoped to achieve this aim of spatial appropriation by the design and construction of a temporary structure through a participatory process.

As Németh and Langhorst (2014, 145-6) discuss, some designers and theorists consider the building of temporary structures in vacant urban land to be a useful way of realising a space's latent potential. Temporary structures in public spaces, it is argued, can facilitate a kind of unconventional "open source" urbanism' (Misselwitz, Oswalt, \& Overmeyer, 2007 cited in Colomb 2012, 138) which is 'contextual and flexible' for city life and particular urban communities (Németh and Longhorst 2014, 145). Temporary structures can emerge as swifter, more creative, and therefore potentially socially transformative, responses to the needs of local populations than typical (permanent or semipermanent) urban design. Participatory design 'refers to the activity of designers and people not trained in design working together in the design and development process' (Sanders 2013, 61), and, if successfully realised, involves non-professionals and non-specialists becoming equal partners in a design process. Previous participatory design studies involving children and youth have demonstrated these participants' capacity to 'reinvent their environments and imaginatively appropriate space' (Birch et al 2016, 1). The design and construction of a temporary structure through participatory design involving Link Club members could therefore, if realised in ideal form, be creative, democratic and, in designing the marginalised into the city, socially transformative.

From a research methods perspective, the project was influenced by the burgeoning literature on participatory research involving youth and children (Askins \& Pain 2011, Brownlie 2009). This approach has argued for a 'reconceptualisation of children within the social sciences as active agents rather than as passive objects of research' (Harris et al 2015, 584), based on an ethos - highly complementary to participatory design - of 'working collaboratively with those who are conventionally situated as research subjects' (Askins and Pain 2011, 806). Such an approach, ideally, provokes 'the dynamic redefinition of social relations' (Literat 2016, 1788) between ages and generations. Like participatory design, therefore, participatory research has transformative and emancipatory potential. There are, however, widely varying degrees by which this is or is not achieved. Such projects at their best genuinely redistribute power through equal decision making and effective outcomes, while less successful efforts merely reproduce hierarchies through tokenistic participation (Cahill 2007, 299; Arnstein 1969 cited in Literat 2016, 1790).

From this perspective, a key advantage of the more informal youth club setting over the disciplinary environment of a school was the potential for voluntary and more open, equal and creative 
participation. The club provided a less formal space for participatory research and its facilitation, a kind of 'in between' place outside of home and school contexts (Livingston \& Sefton-Green 2016, 7). However, as will be demonstrated below, the role of age-based hierarchies remained all too present in complex ways throughout the project. The following section will discuss the participatory design and methods planned and put into practice at Link Club before introducing some of the issues that arose vis-à-vis youth participation.

\section{Participatory design and methods}

The original research approach was to coordinate focus groups with Link Club members. These would explore what members liked to do in their spare time and where, before discussing their views on the Odd Triangle. The plan was for Link Club participants' views to be recorded and subsequently transcribed for thematic qualitative data analysis. After initial focus groups, before the co-design workshops, further focus groups on similar topics and others that emerged during this process would be held at different stages during and after the project. Each group would be convened by one or more of the academic research team running the project. The team consisted of an architect and two sociologists, one of whom has considerable research experience with young people and children.

The participatory design process involved workshops on two evenings a week over a three month period. The workshops' aims were to explore what Link Club members might want to build in the Odd Triangle and how and why this would be of value and potential use to them. Workshops were designed and facilitated by researchers and university student volunteers in a way that prioritised club memberled input, encouraging an open and creative consultation process. Student volunteers were introduced to the project as part of a competition in the university's School of Architecture. Sixteen teams signed up for the competition to design a temporary structure informed by Link Club participation though only eight finally partook in workshops. Two members of each team were invited to visit the club and run co-design twice-weekly workshops, with between three and five teams in the club at one time. At least two of the three researchers would be present during all workshops. Teams mainly consisted of master's students though a small number were undergraduates or students in their year of architecture practice. They were usually mixed in terms of gender and ethnically diverse though with a clear skew towards middle-class backgrounds. Following this consultation process, designs drawn up by the teams would be presented to, and ultimately voted on by, Link Club members. Members would then be invited to partake in the construction process. Though open and participatory it was envisaged that these co-design workshops would allow for similarly relatively formal - in the sense of being clearly situated and defined - recorded, and later transcribed, conversations.

The researchers hoped that this approach would enable an effectively participatory structure for both co-design and data production. With the focus groups in particular this is not, however, how it worked out in practice. On the initial visit to the club the aim was to introduce the project to Link Club members and obtain some preliminary views. Researchers arrived with carefully prepared interview guides, a photograph of the Odd Triangle and a voice recorder, conducting a short joint interview with two older members, encouraged to speak to us by club staff, in the club's kitchen area. With the comings and goings of others they, and the researchers, were often distracted and interrupted. Talking to younger members involved a steeper learning curve. These attempted focus groups saw participants, again encouraged by club staff to be involved, come in and out of the room, perform handstands, approach and pick up the voice recorder, and push disciplinary boundaries by swearing. 
Although many of the relevant questions were asked, and some useful dialogue regarding space and the Odd Triangle initiated, these younger members quickly took control of any conversation, discussing what they wanted to discuss, and asking far more questions of us than we of them.

Many club members were intrigued about why researchers wanted to talk with them, and enthusiastic about discussing the various topics raised, but it soon became clear that the club's social dynamics did not lend themselves to the relatively formal data collection aimed for in focus groups (which may have worked in a more formal research setting such as a school). The researchers were prepared - as with any qualitative fieldwork - to be flexible, improvisatory and pragmatic. However, it was almost immediately evident that our methodology would need to be more flexible and less formal than initially imagined. It was necessary to reconsider the research plans in the face of an unpredictable and highly fluid social space, particularly with regard to participatory methods and the challenging of social hierarchies. Before outlining how this was achieved it is useful to provide a portrait of Link Club as a social space.

\section{Link Club's ethos and a shifting participatory approach}

Link Club has clear disciplinary boundaries regarding the use of language, violence, movement within particular spaces (i.e. not in the staff office), and the consumption of particular items (energy and alcoholic drinks are banned). However, these boundaries are far more relaxed than at school. Signingin is closely monitored, but members are more or less free to come and go from the club and between the different rooms within it as they please. Though the Link Club is doubtless a place of quiet respite for some, for much of the time members' activities are geared towards enthusiastic and energetic enjoyment. The club's younger boys $(11-15)^{1}$ tend to be rowdy and to require the most disciplining by staff in relation to play-fighting (and use of water or equipment such as pool cues to facilitate this), though many also spend time playing calmly on the club's games console. The younger girls prefer less aggressive - but by no means quiet - dancing, gymnastics and drawing games. Older members (16-19) also enjoy playing consoles and music, with groups of older boys, far outnumbering older girls, regularly colonising the pool room, from where many move inside and outside to smoke. Much of the talk among older members is about the next place to obtain tobacco and other consumables, alongside discussions about money and bawdier references to sexual encounters. Most members, of all ages, regularly exchange gossip about members, acquaintances at school or local residents, with the older members' gossip more likely to be sexualised and aided by mobile phone images or text.

Members have an awareness of the club's basic rules, and generally demonstrated a tremendous respect and affection for club staff. The older members involved in the brief focus group seemed to partake partly out of respect for a particular club worker's encouragement. However, there is also a considerable amount of pushing at disciplinary boundaries, whether in relation to the use of profanities and extent of playfighting or in relation to the exchange and consumption of contraband within or at the edges of the club. Link Club's social dynamics can therefore, much of the time, be characterised in relation to Bakhtin's notion of the 'carnivalesque', as the normalised hierarchies of more disciplined spaces such as school are transgressed, albeit temporarily and often briefly, through

\footnotetext{
${ }^{1}$ In what follows the phrase 'younger' boys or girls refers to $11-15$ and 'older' refers to $16-19$. These are more precise than the club's complicated peer-group relations, but with analytic brevity in mind they reflect the most salient friendship groups and some important differences in behaviour.
} 
physicality, bawdiness, crudity and irreverence (Grace and Tobin 2002). Link Club is constructed by these young people as a place to have fun with friends and to build and enact friendships and a particular sense of community, with the carnivalesque elements of the club's social milieu playing a central role in this community-building.

In this context, when reflecting on the focus groups - though many members did seem interested in the project - the researchers' approach had been overly reliant on the adult intervention of a respected club worker encouraging members to be involved. The researchers had been effectively creating, or attempting to, a more adult, disciplinary space within Link Club, and felt that if they could instead work in relation to members' understandings of what the club was for then this would be methodologically advantageous, and far more enjoyable for all concerned. The researchers therefore instigated an approach where members would have more freedom to be involved (or not) in the participatory design processes. The researchers' aim henceforth would be to avoid more synthetic, and in this context over-formalised and hierarchical, research situations and instead embrace the club's unpredictability. They would try to renegotiate their place within the club in a way appropriate to the environment rather than relying, in part at least, on an approach involving precisely the kinds of researcher/researched, adult/youth hierarchies the study aimed to destabilise. Abandoning the idea of focus groups the researchers' instead sought to gradually build up a rapport with club members by variously approaching them or allowing them to approach the researchers during the workshops. Something that had also become clear from the first visit was that for many members the use of a voice recorder was actively disliked and affected the extent to which they were willing to be involved. This led to a reconsideration of recording in favour of taking detailed fieldnotes which were written in situ, usually on the researchers' mobile phones, and in far more detail following workshops.

This approach was also applied to the planning and implementation of co-design workshops. Workshops were designed by students in consultation with academic staff to encourage openness, informality and unpredictability. Eight of the student teams attended Link Club in the first few weeks, asking questions about what members would like to be built in the Odd Triangle, how they might find that building useful to them and what they would do in this space with the new construction. Many students brought along sketching pads on which they would approximate members' suggestions or on which members could sketch their ideas and designs regarding the temporary timber structure. Others brought in building blocks, paint pots or moulding clay for the same purposes. Later in the process, in order to construct something close to a scale simulations of their proposed design, some teams facilitated workshops involving the use of lolly-sticks and blutack or spaghetti and marshmallows. It was found that younger participants were most effectively engaged with through these artistic, creative, often messy activities. The younger girls in particular relished these opportunities. Younger boys were more difficult to engage with due to the challenge of keeping their attention, their higher degree of mobility within the club, and their interest in physically rough more than artistic kinds of play. Many did get involved at different times though, particularly with the more persistent and confident male students who 'bantered' with them. The most effective student teams developed ideas raised in initial workshops and brought sketches and ideas back to Link Club to discuss and clarify with members.

Workshop participation among older members was of more mixed success, especially with the older boys who congregated around the club's pool table. For most student teams it was easier to sit around 
a table consulting the same set of younger girls and boys through artistic activities. On observing this pattern the researchers encouraged students to try and engage with older members by simply approaching and getting to know them. However, many students were shy of the older boys. No older members ever behaved at all aggressively towards anyone involved in the project, but their boisterous, sometimes lewd behaviour was viewed as threatening by the disproportionately middleclass students present. It therefore initially fell more to the researchers to consult the older members on their views regarding the Odd Triangle, a process greatly aided by the rapport developed from playing pool, consoles, or table tennis with them during visits. Four, more confident, male students, better attuned to the playful and often highly masculinised dispositions and language of the older boys, also succeeded in getting to know some of them through bantering, playing pool or computer games. In general, as will be discussed below, most older participants were less interested in the project, but the weeks over which researchers and this small numbers of students 'hung out' with them did involve a considerable amount of discussion on the topic.

After their initial visits most teams considered their consultations to be complete, and for the final six weeks it was largely left to the academic staff and the same above-mentioned four student representatives to continue the workshops and informal consultation, a situation which worked more effectively as the smaller numbers encouraged familiarity. Together the researchers tried to attain a 'feel of life' for the club (Livingston \& Sefton-Green 2016, 48) and to mould the participatory process to the club's informal, enjoyment-centred ethos. Though it is important not to overstate the point the researchers in particular remained unavoidably adult - for most of those in the club during the three month consultation period, especially in the final few weeks, the academic staff and the most persistent students graduated from being what Lawson and Elwood $(2014,212)$ term 'space invaders' to something approaching 'insiders' - people who were routinely expected to be seen in Link Club. In the final few weeks the researchers were approached by members asking for updates on how the project was going or whether particular researchers or students would be returning to the club soon. Nevertheless, while some of the 'traditional pattern[s] of roles and power relationships' usually involved in designer-child/youth exchanges (Birch et al 2016,2) were destabilised, they were certainly not transcended. As the remainder of this article will demonstrate, the extent to which power was genuinely redistributed was very severely constrained by the abiding, broader context of adult power.

\section{Findings 1: The Odd Triangle, stigmatisation and social constraints}

A key finding from the very first day of fieldwork, which was evident throughout the participatory design process, was that the site of the Odd Triangle was very problematic in relation to the aim of spatial appropriation. Most members recognised the photograph of the space presented to them but suggested that they 'don't go there', indicating that this was an area inhabited and used by people other than them. Many immediately decided that whatever was built in the Odd Triangle would be abused or 'ruined'. A group of three younger girls assumed that 'naughty boys' and 'angry people' would ruin the construction by kicking it, 'spit[ting] on it', putting chewing gum on it and 'trashing' it. Their initial ideas for a temporary structure involved an emphasis on security, focusing on the need for CCTV cameras and walls to protect whatever was built there (one suggested that the project should construct 'a bin with a camera in it'). Older members stated that those attending neighbouring bars and nightclubs in the evening would 'smash it up' and/or urinate on it. Project members repeatedly assured club members that the timber would be far too strong for an individual to break by hand or foot, but to little avail. 
As discussed above, Guildhall Walk is an area notorious locally for drunken revelry and violence, and the young people in Link Club were evidently aware of this reputation (whether in relation to 'naughty boys' or inebriated adults). Participants' reactions were no doubt partly symptomatic of an awareness of the broadly held stigmatisation of this area, though they could also be explained by specific sociospatial relationships involving age and class. Researchers' early discussions with members, in which researchers asked them where they went to enjoy themselves in their spare time, made it clear that the Odd Triangle, though very near Solentville from the perspective of more mobile adult lives, was a long way outside what members considered to be their space. Younger members discussed spending most of their time at school, Link Club or in particular parks and playgrounds. Older members suggested similarly limited mobility, restricted to the local area, colleges and places of employment, and occasionally to nearby shopping centres. Participants had little or no significant relationship with the Odd Triangle other than through its reputation, with no imperatives existing, whether from leisure, employment or education, for them to regularly encounter the site.

Spatial relationships and constraints therefore meant that an area less than half a mile away from where most members lived felt radically separate. As Hyndman, drawing on Massey, argues: 'mobility is inherently political' $(2012,248)$, with our subjectivities shaping and constraining which places seem significant, salient and open to us. Age and lifestage are evidently important when it comes to participants' lack of mobility, and Valentine (2004) finds evidence in contemporary Britain for the widespread transmission from parents to children of fear regarding public spaces. Studies of relationships between class and space also demonstrate that while the middle classes are more mobile, have control over their mobility, and live lives involving a 'spatial reach' far beyond their 'contiguous neighbourhood' (Smith 1993 cited in Morley 2002, 197), those living in more deprived areas, especially children (Sutton 2008, 538), are considerably more restricted in their use of space. Such children are furthermore found to demonstrate a greater sensitivity towards the potential for violence and risk than children from more affluent backgrounds (Sutton 2008, 545). In this context it is unsurprising that initial discussions did not provoke responses to chime with the more radical ideals of temporary urban design. Indeed, the very non-permanence seen by many designers as a strength was interpreted as unsuitably fragile for this kind of unruly and insecure adult space.

The cynical views voiced from day one of fieldwork regarding the structure's future coupled with the sense of dislocation from the Odd Triangle meant that the project's aim of spatial appropriation faced formidable obstacles. Participatory design can be relevant at each stage of a design process, but Sanders $(2013,68)$ argues that, for maximum impact in terms of societal value, equal participation should be a core feature from project inception. Participatory research involving young people has likewise demonstrated the benefits of involving participants in each stage of the research process inclusive of 'problem identification' (Cahill 2007, 301). Link Club members' involvement in spatial appropriation was therefore 'executory' in character - that is, task-based with regard to a predesigned project - rather than structural in terms of their agentic involvement in setting the project's general parameters (Literat 2016, 1796). The researchers' arrival at the club with a pre-arranged, problematic site thus violated some core principles from both research and design participatory perspectives. However, recognising that these principles are ideals and very rarely consistently achieved, the researchers did not wish to treat this problem as necessarily terminal to the project's aims, particularly as many club members clearly remained keen to participate in the project. Soon the 
participatory process became enveloped within the Link Club's general atmosphere of play, sociability and enjoyment.

\section{Findings 2: The Odd Triangle, imagination and transgression}

The scope of the project - a temporary timber structure - was continuously restated to club members. However, the expression of wide-ranging, imaginative and fantastical ideas became central to the participatory design process, dominating the sketches, drawings and models produced through workshops. By far the most popular idea among younger members was a space dedicated to play of some kind, and many workshops were spent drawing, moulding and colouring-in potential designs. Ideas included a hangout with consoles at the top of a treehouse type structure, a slide leading to a trampoline, a slide going across the busy road neighbouring the site, a 'massive statue for climbing', and a zip wire from Link Club. The last of these, though fantastical, firmly situated the Odd Triangle in relation to club members' lives in Solentville, again suggesting localised constraints on participants' sense of mobility and agency. Some of the most popular ideas - such as access to consoles and climbing frames - were notably similar to what was available more locally in Link Club or nearby playgrounds. Every co-design workshop with younger participants saw disciplinary boundaries pushed through swearing, references to sex and bodies, or the giving of scatological nicknames to researchers. Workshops were interspersed with (often obscene) gossip and sometimes involved the defacement or temporary stealing of materials such as pens and other such playful challenging of adult authority.

Many of the suggestions from older members, usually expressing their views verbally rather than through visual media, were more prosaic in nature. In contrast to the younger participants' focus on their own play and enjoyment they were more concerned with the wider community than their own needs. Suggestions included the construction of a homeless shelter or amenities for late-night revellers such as a smoking shelter. These ideas were primarily altruistic, and often seemed to be a polite response to researchers' requests rather than representing meaningful interest. The response by one older participant, when probed for further details about the suggestions he had made, of screwing up his face and saying 'I'll have to get back to you on that' became a running joke.

The only ideas of older members involving their ownership of the site were usually tongue-in-cheek and fantastical. Examples included a Tardis-like ${ }^{2}$ structure in which a pool-hall would be situated, a swimming pool, or a statue of a friend of theirs. Other ideas were profit- and prestige-oriented, such as a museum or a bar (with an alcohol licence running later than other nearby establishments) for which they could charge entry fees. Some older male members only discussed, or were attentive to, consultations involving particular female students who they apparently found attractive. Just as younger members pushed boundaries during their workshops, discussions with older boys were peppered, in the background or directly within conversation, with references, innuendo or otherwise, to sex and substance use. This transgressive, boundary-pushing behaviour was more adult-oriented than the behaviour of younger members, involving as it did the confident adoption of, or references to, adult behaviour and practices seen as inappropriate for children. As conversations continued, it became clear that the process of discussing the Odd Triangle and conversing with researchers and

\footnotetext{
${ }^{2}$ The Tardis is the time-travelling vessel of science-fiction character Doctor Who. It is famous for looking small from the outside but being large on the inside once entered.
} 
students was an enjoyable experience for many older club members, but that any appropriation of the space for their own purposes or needs was not being treated very seriously by most.

Many Link Club members' responses to the co-design process could therefore be described as playful if we consider play to be a practice with 'no external goal guiding' it (Birch et al 2016,5). For members of all ages there was little indication that they considered the actual feasibility of many of their ideas to be important. The most interested and enthusiastic involvement occurred in relation to these more fantastical and imaginative suggestions in the context of the continuous reaffirmation of an ethos and community founded on the pushing of disciplinary boundaries. Members' focus on enjoyment and their routine acts of transgression during workshops, suggest the enacting of particularly oppositional youth - perhaps specifically working-class youth - identities (Willis 1997, Archer et al 2007). Even the older members' more adult-oriented conversations and ideas largely adopted and mimicked transgressive, hedonistic adult behaviour rather than the 'respectable' behaviour associated norms (in the middle-class popular imagination at least) with adult middle-class. Class- and age-related effects were, therefore, crucial again in aiding the appropriation of the co-design process if not the Odd Triangle itself.

Link Club members, in effect, collectively shifted the terms of the participatory approach away from the researchers' original aims (cf Cahill 2007, 304). Rather than the more typical pattern found in participatory research of adults constraining young people's participation in relation to adult norms (e.g. Livingston \& Sefton-Green 2016, 57), one danger of which is the manufacturing of 'a more-orless acceptable form of [youth] voice' (Kraftl 2013, 15), it was, here, found that by adapting the project to the ethos of Link Club the researchers' aims were being distorted by youth participants. While some ideals of youth participatory involvement as participant-driven were being adhered to in terms of 'free experimentation and play' (Clark 2011, 333), as the project gravitated towards participants' interests the extent to which researchers were facilitating spatial appropriation became secondary to, and sometimes effectively absent from, the project. From this perspective, club members, by appropriating the participatory process and redefining its parameters, were effectively achieving structural rather than merely executory involvement (Literat 2016, 1796). At the same time, however, the workshops also demonstrated how the club's peer-group dynamics ultimately remained bound up with, and routinely reactive to, adult social hierarchies, albeit largely through their transgression. The conclusion will discuss this point in further detail following a discussion of the project's final stage.

\section{Findings 3: The final design and construction process}

Following three months of workshops Link Club members were presented with eleven final designs by students and researchers over two evenings before a deciding vote, with individual members naming a top three. The club was abuzz during this period, with the voting process setting off its own interesting dynamic. Many older members took great pleasure in assuming positions of apparent expertise, with some adopting the authoritative role and language of TV competition judges (see The $X$-Factor or Dragons Den), through, for example, their use of phrases such as 'it has to be a no to that one from me'. They thus both parodied and adopted hierarchical positions associated with adult wealth, power and prestige in a way that was knowingly discordant with the setting and stakes of the process. 
The winning design, by a considerable margin, was \#IHEARTPOMPEY ${ }^{3}$ which combined the elements of play and local utility threaded through the consultation process. \#IHEARTPOMPEY is built from timber and shaped like a heart (Figure 2). The structure is designed to have a swing hanging from its apex and includes slats in which clay tiles can be placed. A significant disappointment following the adoption of the \#IHEARTPOMPEY design was the rejection by local government bodies of the swing component on health and safety grounds. Some of the younger members in particular were disappointed by this absence which greatly reduced the potential for play. The tile-creation process, however, was very successful in enabling a sense of ownership for many of these participants, with tile workshops at Link Club providing another messy and enjoyable experience. Using paints and moulds, members stamped their ownership on the tiles and ultimately the \#IHEARTPOMPEY construction, creating personalised tiles and others representing Link Club, Portsmouth or Britain. The altruism that ran through all of the researchers' dealings with club members was demonstrated by participants making tiles for friends who couldn't attend on the evenings in question. The carnivalesque aspect remained present, however, with some younger participants (usually only temporarily) writing crude phrases into the clay.

Figure 2: The \#IHEARTPOMPEY temporary structure

Although researchers attempted to encourage as many older Link Club members as possible to get involved in the construction of \#IHEARTPOMPEY, only three attended over the four days of construction. These members were engaged with by students and staff, who were friendly and welcoming throughout, but they only stayed for half a day on the first and only a few hours on the second day, without returning during the final two days of construction. The participant who had attended the longest period of time later grumbled to one researcher, in front of several other club members, that they had found the construction work 'boring'. This specific rejection may have been another expression of the general anti-adult ethos characteristic of Link Club, or it may be that the prestige and empowerment found to be central to many older participants' ideas and desires during the design process was not sufficiently met by the kinds of manual labour involved in the construction (sawing, screwing in nails, and so on).

For the official opening of \#IHEARTPOMPEY seven Link Club members, mostly younger participants, attended. Three younger girls who had been very involved in the workshops seemed to enjoy themselves, but others present spoke about the structure in very derogatory terms. An older club member suggested that she now regretted the inclusion of her name in one of the tiles. Three younger boys expressed especially harsh views, with one describing the structure's shape as a 'retarded heart'. These boys sat for a few minutes, at the edges of the Odd Triangle, facing away from the construction looking bored, before leaving. Everyone the researchers spoke to continued to discuss the likelihood of its destruction and the futility of the 'no climbing' signs (one member made a show of, though ultimately did not go ahead with, the act of climbing it herself). Another two older members visited towards the end of the launch event. Asked whether they liked \#IHEARTPOMPEY, they replied that they did - stating with pride that they had voted for this design - before affectionately calling Guido a 'dude' and leaving (they had been present for less than a minute).

33 'Pompey' is a slang term for the city of Portsmouth. 
In the days and weeks following the project researchers spoke again to Link Club members. Many expressed a sense of pride and ownership in \#IHEARTPOMPEY thanks to their involvement in the design, the voting process, and the inclusion of their tiles. However, there is no escaping the fact that their attitude towards the project was sceptical, often cynical. No member suggested that they used the space, though some hoped it would be useful for smokers coming out of nearby clubs when it rained. One of the most discussed and agreed-with comments during a post-construction visit to the club was made by an older member who suggested that the slats of the structure would be useful for the stashing of drugs by dealers and users in that area. The ever-overriding concern from these visits was the structure's ultimate ruination. At the time of writing \#IHEARTPOMPEY remains intact, though in March 2017 most of its tiles were vandalised (Figure 3). Members' perceptions and suspicions surrounding this adult space, coloured by violence and crime as they were, were thus partly vindicated.

Figure 3: Vandalised tiles on \#IHEARTPOMPEY

\section{Conclusion}

As Allen and Hollingsworth $(2013,502)$ note, 'not all subjects can "lay claim" to places' equally. For Link Club members, interrelating social and spatial conditions were not ripe for their appropriation of the Odd Triangle, during or after the design and construction of \#IHEARTPOMPEY. In previous studies designers have reported children and youth to be 'free from many constraints imposed by the adult world' (Birch et al 2016, 8), but though imagination and creativity were central to the participatory design process, it was the young members of Link Club rather than the adult designers who felt constrained by a space they considered to be unruly, adult and violent. Relationships involving space, life-stage and socioeconomic location delimited the extent to which members could personally invest in each of the project's stages, meaning that most members did not feel 'designed in[to]' the city (Bodnar 2015, 2102) by the end of the project to the extent that the researchers had hoped. While previous participatory research involving children suggests that 'messy' interactions involving creative and artistic methods are particularly effective in enabling socially transformative research (Askins and Pain 2011), the difficulty of constructing a representation of Link Club member's ideas, coupled with the requirement for the design and construction of a safe, officially-sanctioned structure in the adult city, effectively tidied up many of the messy and creative elements produced during the workshops. While temporary structures are rightly considered to provide flexible and context-specific uses of vacant spaces for urban communities (Németh and Langhorst 2014), they can evidently also have their limitations in relation to particular social groups and locations.

Though the aim of spatial appropriation was, at best, a qualified success, the participatory design process was undoubtedly appropriated in relation to the peer-group dynamics of Link Club. While playing with, mocking or rejecting, in part or in whole, the aims of the project, Link Club members agentically negotiated and reaffirmed youth identities and a sense of community founded upon these same practices of playing, mocking and rejecting. Although the overall project did not finally redistribute power in any sustained way, age- and class-based hierarchies were nevertheless temporarily, contingently destabilised, as researchers, students and club members alike adapted the participatory methods to the club's ethos. In this way, from an analytic perspective focusing on expressive more than instrumental dimensions of participation (Kraftl 2013, 15), a degree of youth agency was enabled, with fieldwork demonstrating slippages between structural and executory 
participation (Literat 2016, 1796). At the same time, however, it is important to note that such agency was limited, as youth participation remained consistently reactive to adult norms; and when the project was most effectively participatory, as club members shifted the project's parameters, the aim of spatial appropriation fell further away. Therefore, while the Odd Triangle's location constrained youth involvement in the project, when participatory facilitation was more effective this constrained the project's more transformative, sustainably redistributive goals.

It is possible that youth rather than adult facilitation could have helped reduce some of the oppositional, transgressive dynamics during the co-design process. These may have been encouraged by the mere presence of adult facilitators, regardless of how informal or open workshops were, as well as by the fact that the research site was adult-controlled and thus may have provoked this particular peer-group response. However, even if the resources required for such an approach had been available, it is unclear whether peer facilitation, by shifting adult control a step or two further away, would have significantly altered the interests and motivations of club members, shaped as these are by broader disciplinary frameworks and expectations; or whether research outside of an adultcontrolled site or institution would have been practically and ethically feasible. It is also unclear whether a less oppositional outcome would be desirable, somehow more genuinely agentic, or, again, at all sustainably redistributive of power; especially given that peer researchers often adopt adult social mores, effectively 'policing' their peers in a research context (Barker and Weller, 2003), as was briefly seen in the present project during the vote for the final design.

With those questions in mind, this paper argues that those engaged in participatory design and research with transformative aims should recognise that - in the context of abiding adult power - youth and adult relationships and perspectives are sometimes structurally irreconcilable. From a design perspective, club members' interests and motivations were perhaps not representable anywhere in the city without the domestication of their transgressive, imaginative and fantastical character to (middle-class) adult norms. The symbolic space in which these playful, imaginative, often oppositional ideas were located, and in relation to which a sense of community in Link Club was constructed, rendered these ideas impossible to represent in the adult city without the loss of much or all of their constitutive playful and oppositional character. Any design and temporary structure would inevitably involve participants' ideas being refracted through the classed and adult rules, norms and practices which strictly regulate urban space, with the more carnivalesque ideas, furthermore, raising some important ethical issues (cf Vanderbeck 2008). Ultimately this article's findings suggest that those aiming for genuinely transformative redistributions of power through child/youth participatory approaches need to be careful about underestimating the extent to which marginalised young peoples' interests, enjoyment and desires are framed by adulthood, and by social inequalities and power-relations with deep and durable structural foundations. 


\section{Literature cited}

Allen, K., \& Hollingworth, S. (2013). 'Sticky subjects' or 'cosmopolitan creatives'? Social class, place and urban young people's aspirations for work in the knowledge economy. Urban Studies, 50(3), 499-517.

Archer, L., Hollingworth, S., \& Halsall, A. (2007). University's not for Me-I'm a Nike Person': Urban, Working-Class Young People's Negotiations ofStyle', Identity and Educational Engagement. Sociology, 41(2), 219-237.

Askins, K., \& Pain, R. (2011). Contact zones: participation, materiality, and the messiness of interaction. Environment and planning D: society and space, 29(5), 803-821.

Barker, John, and Susie Weller. "“Is it fun?" Developing children centred research methods." International journal of sociology and social policy 23.1/2 (2003): 33-58.

BBC. (2011) Portsmouth's Guildhall Walk among 'violent' streets. BBC Hampshire \& Isle of Wight. http://www.bbc.co.uk/news/uk-england-hampshire-12332347

Birch, J., Parnell, R., Patsarika, M., \& Šorn, M. (2016). Creativity, play and transgression: children transforming spatial design. CoDesign, 1-16.

Bodnar, J. (2015). Reclaiming public space. Urban Studies. Vol. 52(12) 2090-2104

Brownlie, J. (2009). Researching, not playing, in the public sphere. Sociology, 43(4), 699-716.

Cahill, C. (2007). Doing research with young people: Participatory research and the rituals of collective work. Children's Geographies, 5(3), 297-312.

Clark, L. S. (2011). Parental mediation theory for the digital age. Communication theory, 21(4), 323343.

Colomb, C. (2012). Pushing the urban frontier: temporary uses of space, city marketing, and the creative city discourse in 2000s Berlin. Journal of urban affairs, 34(2), 131-152.

Department for Communities and Local Government. (2015). Indices of Multiple Deprivation in England 2015.

Doron, G. M. (2000). The dead zone and the architecture of transgression.City, 4(2), 247-263.

Grace, D. J., \& Tobin, J. (2002). Pleasure, creativity, and the carnivalesque in children's video production. In The arts in children's lives edited by Liona Bresler and Christine Thompson pp. 195-214). Springer.

Harris, C., Jackson, L., Mayblin, L., Piekut, A., \& Valentine, G. (2015). 'Big Brother welcomes you': exploring innovative methods for research with children and young people outside of the home and school environments. Qualitative Research, 15(5), 583-599.

Harvey, D. (2008). The right to the city. The City Reader, 6, 23-40.

Hyndman J, 2012, "The geopolitics of migration and mobility" Geopolitics 17(2) 243-255. 
Jenkins, H., \& Carpentier, N. (2013). Theorizing participatory intensities: A conversation about participation and politics. Convergence, 19(3), 265-286.

Kraftl, P. (2013). Beyond 'voice', beyond 'agency', beyond 'politics'? Hybrid childhoods and some critical reflections on children's emotional geographies. Emotion, Space and Society, 9, 13-23.

Lawson, V., \& Elwood, S. (2014). Encountering poverty: Space, class, and poverty politics. Antipode, 46(1), 209-228.

Literat, I. (2016). Interrogating participation across disciplinary boundaries: Lessons from political philosophy, cultural studies, art, and education. new media \& society, 18(8), 1787-1803.

Livingstone, S., \& Sefton-Green, J. (2016). The class: Living and learning in the digital age. NYU Press. Morley, D. (2002). Home territories: Media, mobility and identity. Routledge.

Németh, J., \& Langhorst, J. (2014). Rethinking urban transformation: Temporary uses for vacant land. Cities, 40, 143-150.

Sanders, E. B.-N. (2013) Perspectives on Design in Participation. In Wer Gestaltet die Gestaltung? Praxis, Theorie und Geschichte des Partizipatorischen Designs, Mareis, C., Held, M. and Joost, G. (Hg.), Verlag.

Schmidt, S., \& Németh, J. (2010). Space, place and the city: Emerging research on public space design and planning. Journal of Urban Design, 15(4), 453-457.

Sutton, L. (2008). The state of play: Disadvantage, play and children's well-being. Social policy and society, 7(04), 537-549.

Valentine, G. (2004). Public space and the culture of childhood. Abingdon: Routledge.

Vanderbeck, R. M. (2008). Reaching critical mass? Theory, politics, and the culture of debate in children's geographies. Area, 40(3), 393-400.

Willis, Paul E. (1977) Learning to labor: How working class kids get working class jobs. New York: Columbia University Press. 